Revue d'histoire de l'Amérique française

REVUE D.HISTOIRE DE L'AMÉRIQUE FRANÇAISE

\title{
JOUVE, Odoric et Archange GODBOUT, avec la collaboration de Hervé BLAIS et René BACON, Dictionnaire biographique des Récollets missionnaires en Nouvelle-France (Montréal, Bellarmin, 1996), 903 p.
}

\section{Dominique Deslandres}

Volume 51, numéro 3, hiver 1998

URI : https://id.erudit.org/iderudit/005393ar

DOI : https://doi.org/10.7202/005393ar

Aller au sommaire du numéro

Éditeur(s)

Institut d'histoire de l'Amérique française

ISSN

0035-2357 (imprimé)

1492-1383 (numérique)

Découvrir la revue

Citer ce compte rendu

Deslandres, D. (1998). Compte rendu de [JOUVE, Odoric et Archange GODBOUT, avec la collaboration de Hervé BLAIS et René BACON, Dictionnaire biographique des Récollets missionnaires en Nouvelle-France (Montréal, Bellarmin, 1996), 903 p.] Revue d'histoire de l'Amérique française, 51(3), 462-462. https://doi.org/10.7202/005393ar d'utilisation que vous pouvez consulter en ligne. 


\section{NOTE BIBLIOGRAPHIQUE}

JOUVE, Odoric et Archange GODBOUT, avec la collaboration de Hervé BLAIS et René BACON, Dictionnaire biographique des Récollets missionnaires en Nouvelle-France (Montréal, Bellarmin, 1996), 903 p.

Longtemps attendu des spécialistes, le Dictionnaire biographique des Récollets missionnaires en Nouvelle-France marque une avancée décisive dans l'histoire méconnue des récollets. Il se révèle un indispensable instrument de travail d'une considérable érudition et d'une excellente présentation. Suivis du dictionnaire proprement dit, trois brefs chapitres introductifs posent les balises nécessaires à la compréhension de la présence récollette au Canada. Le premier chapitre résume ainsi l'histoire de l'ordre, en insistant sur son ministère en France et à l'étranger (prédication populaire, missions à la contagion, aux armées, aux hôpitaux, évangélisation des non-chrétiens, diplomatie); le second analyse l'œuvre missionnaire des récollets en Nouvelle-France en soulignant, entre autres, les divers types d'apostolats et en retraçant, avec force tableaux, les lieux d'activité de l'ordre; le dernier chapitre met à jour le répertoire des 345 récollets qui ont œuvré en Nouvelle-France en élaguant les «intrus» des listes imprimées jusqu'à présent et en offrant une liste la plus complète possible.

S'il est vrai que le dictionnaire, qui constitue la plus grande partie de l'ouvrage, représente l'œuvre d'une vie, celle d'Odoric Jouve qui y a consacré plus de 50 ans, il faut souligner et saluer l'énorme travail accompli par René Bacon, qui, trop modestement à notre goût, semble se cacher derrière ses prédécesseurs Jouve, Godbout et Blais, alors que, loin de se contenter d'éditer avec brio l'ouvrage, il signe, à lui seul, près de la moitié des 333 notices (il en signe seul 139 et collabore à 28 autres alors que Jouve en signe 97 et en cosigne 24). Les notices que l'on retrouve ici complètent celles qui apparaissent dans le Dictionnaire biographique du Canada qui, par contrainte éditoriale, avaient dû être considérablement raccourcies. Leur longeur varie selon les sources disponibles et la plupart abondent en détails souvent inédits et comblent, par de nombreuses notes en bas de pages, bien des lacunes documentaires. 